\title{
Inserção das mulheres em uma cooperativa agrícola do sul de Santa Catarina: Programa Mulheres Cooperativistas
}

\author{
Insertion of women in an agricultural cooperative in the south of Santa Catarina: \\ Women Cooperatives Program
}

\author{
Erica Tonetto de Souza' ${ }^{*}$ ) \\ Melissa Watanabe ${ }^{2}$ \\ Cristina Keiko Yamaguchi ${ }^{3}$ \\ Gisele Silveira Coelho Lopes ${ }^{4}$
}

\section{Resumo}

As mulheres encontram-se cada vez mais no mercado de trabalho e lutam por direitos igualitários, obtendo voz ativa em busca de seus ideais e consequentemente conquistando seu espaço na sociedade. Deste modo, o presente estudo teve por objetivo descrever como é abordada a liderança feminina e de que modo ocorreu a inserção do Programa Mulheres Cooperativistas em uma Cooperativa agrícola de Santa Catarina. O procedimento metodológico utilizado foi exploratório, descritivo, bibliográfica e estudo de caso por intermédio de questionário e aplicado em um grupo de 18 mulheres participantes do referido núcleo feminino e a partir de entrevista realizada com o presidente da mesma organização. Resultados apontaram que por intermédio do núcleo feminino as mulheres conquistaram mais espaço para expor suas ideias e opiniões no quadro social da cooperativa, em contrapartida a cooperativa em questão também se beneficiou, pois através do núcleo a mesma obteve maior participação dos associados. A pesquisa também evidenciou que as respondentes sentiram grande satisfação em fazer parte do referido núcleo, pois adquiriram maior entendimento do funcionamento da cooperativa, maior reconhecimento e integração familiar, participação nos processos decisórios, novos laços de amizades, conhecimentos e ainda relataram que reconquistaram sua autoconfiança e autoestima.

Palavras-chave: Liderança feminina, Cooperativismo, mulheres cooperativistas.

1 Dra.; Geociências e Meio Ambiente; Universidade Estadual Paulista Júlio de Mesquita Filho, UNESP, Brasil; Atua nos temas: hidroquímica, qualidade de água subterrânea, Isótopos de $\mathrm{Pb}$ na atmosfera e $\mathrm{Th}$ e $\mathrm{Pb}$ em águas subterrâneas; Endereço: Universidade Estadual Paulista Júlio de Mesquita Filho, Instituto de Geociências e Ciências Exatas de Rio Claro, Departamento de Petrologia e Metalogenia. Avenida 24-A, 1515, Bela vista. CEP: 13506-900 - Rio Claro, SP Brasil E-Mail: erica.souza@ coopersulca.com.br $\quad\left({ }^{*}\right)$ Autor para correspondências

2 Dra.; Agronegócios; Universidade Federal do Rio Grande do Sul, UFRGS, Brasil; Professora permanente do Programa de Pós-graduação em Desenvolvimento Socioeconômico da Universidade do Extremo Sul Catarinense - UNESC; Endereço: Universidade do Extremo Sul Catarinense, Programa de Pós-Graduação em Desenvolvimento Socioeconômico. Av. Universitaria, 1105, Bairro Universitario. CEP: 88806000 - Criciúma, SC - Brasil E-Mail: melissawatanabe@unesc.net

3 Dra.; Engenharia e Gestão do Conhecimento; Universidade Federal de Santa Catarina, UFSC, Brasil; Professora Colaboradora do Programa de Pós-Graduação em Desenvolvimento Socioeconômico na Universidade do Extremo Sul Catarinense; Endereço: Universidade do Extremo Sul Catarinense. Rua Dr. Jorge Bleyer, 667, Conta Dinheiro. CEP:88508618 - Lages, SC - Brasil E-Mail: criskyamaguchi@gmail.com

4 Doutoranda; Administração; Universidade do Vale do Itajaí, UNIVALI, Brasil; Professora do Curso de Administração, Comércio Exterior e Tecnologia em Gestão Comercial em EAD da Universidade do Extremo Sul Catarinense - UNESC; Endereço: Universidade do Extremo Sul Catarinense, Conselho Universitário. Avenida Universitária, 1105,Centenário. CEP:88806000 - Criciúma, SC - Brasil E-Mail: giselelopes@unesc.net

\begin{tabular}{llllll}
\hline Ambiência & Guarapuava (PR) & v.14 n.8 & p. 315-330 & Maio/Ago 2018 & ISSN 1808 - 0251
\end{tabular}




\section{ABSTRACT}

Women find themselves increasingly in the labor market and fight for equal rights, obtaining an active voice in search of their ideals and consequently conquering their space in society. Thus, the present study aimed to describe how the female leadership is approached and how the insertion of the Cooperative women's program occurred in an agricultural cooperative in Santa Catarina. The methodological procedure used was exploratory, descriptive, bibliographical and case study by means of a questionnaire and applied in a group of 18 women participants of said female center and from an interview with the President of the same organization. Results showed that, through the female center, women gained more space to expose their ideas and opinions within the cooperative's membership, in contrast, the cooperative in question also benefited, since through the female center it obtained greater participation from the members. The research also showed that the respondents felt great satisfaction in being part of this nucleus, as they acquired a greater understanding of cooperative functioning, greater recognition and family integration, participation in decision-making processes, new ties of friendship, knowledge and also reported that they regained their self-confidence and self-esteem.

Keyword: Women's leadership, Cooperatives, Women's cooperatives.

\section{INTRODUÇÃO}

As mulheres ao longo dos tempos lutam por igualdade e aceitação tanto no mercado de trabalho, como na sociedade em geral. No passado, era responsabilidade somente dos homens o sustento do lar, sendo eles provedores financeiros bem como as decisões perante a família. Mas este cenário em que a mulher exercia apenas a função de dona do lar, mãe e esposa, vem mudando por intermédio de movimentos sociais ocorridos em todo mundo, ocasionando assim mudanças constantes (PEREIRA; SANTOS; BORGES, 2005).

Porém, mesmo com o crescimento no mercado de trabalho, a mulher ainda se depara com algumas dificuldades e preconceitos, pois muitas permanecem com todas as atividades do lar, necessitando, muitas vezes conciliar casa, filhos, marido e trabalho (BRUSCHINI, 2012). Outro fator relevante é que a mulher ainda apresenta na maioria das profissões uma desigualdade salarial.

Segundo Gomes (2005), devido a sua flexibilidade, sensibilidade, capacidade de trabalhar em grupo, instinto de liderança e sua habilidade de administração do cotidiano, as mulheres vêm chamando a atenção no mercado de trabalho, destacando-se nos mais diversos cargos.

Essa realidade também está acontecendo nas cooperativas agropecuárias, local que tradicionalmente são representadas na sua maioria pelo gênero masculino, vêm recebendo aos poucos a presença feminina. Uma forma de ocorrer esta inserção é a incorporação de núcleos femininos, que tem por objetivo melhorar a autoestima da mulher tornando-a mais autoconfiante, melhorando assim, sua interação familiar e com reflexos na sua maior participação na produção rural e na cooperativa (SESCOOP, 2012).

No Estado de Santa Catarina existem 263 cooperativas nos mais diversificados ramos, sendo estes, no ramo agropecuário, saúde, crédito, consumo, infraestrutura e transporte. Cooperativas estas que hoje contam com mais de 1 milhão de pessoas associadas, e emprega em média 42.634 
funcionários (SESCOOP, 2012). É nesse ambiente que o presente estudo tem por objetivo descrever de que forma percebeu-se a liderança feminina a partir da inserção do núcleo feminino em uma Cooperativa de Santa Catarina.

Esta investigação fundamenta-se a partir do entendimento referente à liderança feminina, em sua primeira parte de sua fundamentação. Em seguida aborda-se um breve histórico da cooperativa, objeto de estudo, seguido pela explicação do programa mulheres cooperativas em si.

\section{Liderança feminina}

Entende-se por liderança o ato de chefiar, comandar e orientar um determinado grupo de pessoas, ou seja, alguém que guie e conquiste a confiança dos colaborados influenciando no seu comportamento (CARREIRA 2001). Para isso, é necessário que um bom líder saiba identificar e entender seus concorrentes e colegas de trabalhos para que obtenha melhor relacionamento com estes, proporcionando assim, mais oportunidades, evitando desentendimentos e prevendo contatos profissionais benéficos (DEL PE,2008). Já para Oliveira e Marinho (2005), A liderança é o ato de ter empatia por seus liderados e saber colocar-se no lugar dos mesmos para melhor desempenho de suas atividades, trabalhando em equipe e harmonia como uma família.

Segundo Carreira, Ajamil e Moreira (2001), com a necessidade de adaptação às novas condições que a economia impusera em tempos de guerra, fez-se necessária à inserção da mesma no mercado de trabalho. Assim, as mulheres tiveram uma maior força com a I e II Guerra Mundial, pois com os homens convocados a batalha, elas precisaram ocupar os trabalhos nas lavouras, nas indústrias, comércios e prestadoras de serviços para dar continuidade ao processo produtivo. Sendo assim, perante a ausência dos maridos as mulheres tiveram que também assumir os postos masculinos em seus lares, cuidando dos negócios e das atividades antes exercidas pelo cônjuge a fim de suprir às necessidades da casa. Consequentemente, a mulher acabou modificando sua estrutura familiar e conquistando uma nova postura na sociedade. Porém muitas mulheres trabalhadoras acabaram expostas ao mais diversos tipos de explorações e abusos, os quais eram provenientes da falta de leis que lhes desses garantia de dignidade como mulher e como trabalhadora (SOUZA; SANTOS, 2014; VIEIRA; SILVA, 2001).

Algumas leis foram criadas a fim de proteger as mulheres e de acordo com o Artigo 113, inciso 1 da Constituição Federal Brasileira de 1932, ficou estabelecido que a mulher trabalhadora não podem ter diferenciação de salário por distinção de sexo, não podem ser despedida por estar grávida, tem direito a dispensa de 4 semanas antes e após o parto e a mesmas encontram-se proibida de trabalhar das 22 horas às 5 da manhã (SOUZA; SANTOS, 2014).

Em 1975, no México durante a primeira Conferência Mundial de Mulheres foram apresentadas propostas e recomendações, a fim de melhorar as condições de vida das mulheres no mundo e permitir acesso as mesmas oportunidades que o gênero masculino. Houve muitos avanços na história feminina, porém ainda pode-se observar a distinção entre homens e mulheres, principalmente no que se refere ao crescimento profissional e desigualdade salarial (VIEIRA; SILVA, 2001; TORREÃO, 2007; BRUSCHINI, 2012).

Vale ressaltar que é reconhecível o grande impacto da participação das mulheres no mercado de trabalho, pois as mulheres passaram a contribuir com a força produtiva do país, com o aumento da renda familiar, aumento em seu grau de escolaridade e também a diminuição de fecundidade. Observa-se que as mulheres vêm abrindo duas vezes mais empresas que os homens, pois no 
cenário econômico percebe-se que um terço de todos os negócios são pertencentes às mulheres (VIEIRA; SILVA, 2001; ANDREOLI; BORGES, 2007).

Dentre os motivos pelos quais as mulheres entraram no mundo do empreendedorismo é possível apontar, a sua percepção de oportunidade no mundo dos negócios, sua experiência, falta de oportunidade de emprego, flexibilidade de horários, demissão e até por descontentamento no anterior trabalho exercido e também a fim de adquirir sua realização pessoal e independência. O crescimento do setor de serviços e terceirização foram uns dos principais impulsionadores da mulher no mercado de trabalho (ANDREOLI; BORGES, 2007).

Há destaque do gênero feminino no mundo dos negócios devido a sua múltipla funcionalidade, capacidade de improvisar, sensibilidade e espírito de cooperação, pois a mulher empreendedora possui habilidade da aplicação da estratégia ganha-ganha, a qual a mesma procura suprir às necessidades das pessoas que a rodeiam (ANDREOLI; BORGES, 2007).

Para algumas mulheres esse ambiente pode ser profundamente estressante, pois devido a sua capacidade de lidar com grande quantidade e variedade de responsabilidades, ela acaba em muitos casos resultando em estresse. Este estresse é causado por alguns fatores como, por exemplo, o medo de fracassar, a sindrome da super-mulher e a falta de valorização externa como mostrado no Quadro 01 (CARREIRA; AJAMIL; MOREIRA, 2001).w

\section{Quadro 01 - Causas de estresse feminino}

O medo de fracassar trata-se do medo que a mulher tem de buscar cargos de responsabilidade, pois na sua percepção elas devem ser escolhidas para o cargo, mas enquanto isso não acontece elas ocupam cargos inferiores e de maior desgaste físico, o que acaba resulta na diminuição de sua autoestima.

A síndrome da super-mulher refere-se a grande quantidade de atividades desempenhadas pela mulher. A mulher desdobra-se para conciliar a vida familiar, afetiva, profissional e formação intelectual, o que acaba desgastando a sua saúde.

A falta de valorização externa acontece devido a sua dificuldade de ocupar cargos de liderança nas organizações, as quais não dão devido reconhecimento ao serviço prestado pelas mulheres, resultando no estresse feminino por trabalhar demais sem reconhecimento.

Fonte: Adaptado de CARREIRA; AJAMIL; MOREIRA, 2001.

\section{Um breve histórico da cooperativa e o Programa Mulheres Cooperativistas}

A cooperativa selecionada está localizada em um município que apresenta aproximadamente 12 mil habitantes, possui uma área de 230 quilômetros quadrados e encontra-se localizada no extremo sul catarinense, equidistante aproximadamente $250 \mathrm{~km}$ de Florianópolis e de Porto Alegre, sendo na sua maioria residentes na zona rural (IBGE, 2013).

A cooperativa apresentou seu início em 1964 com a união de pouco mais de 200 produtores, objetivando unir forças para superar as dificuldades que possuíam em comum (OCESC, 2013). Com o passar do tempo a cooperativa cresceu e em 1979 os produtores de municípios vizinhos, foram incorporados ao grupo e com isso a cooperativa ampliou sua área de atuação para todo o Sul Catarinense (OCESC, 2013).

Hoje a cooperativa é composta por aproximadamente 2.500 famílias de agricultoras e conta com um quadro de 260 funcionários. Ela é uma das significativas geradoras de emprego e renda da região, sendo que contribui anualmente com uma quantidade considerável de tributos aos cofres públicos do município (OCESC, 2013). 
O núcleo feminino iniciou suas atividades com duas turmas-piloto constituídas por mulheres de duas cooperativas de Santa Catarina no período de Abril a Agosto de 2013. Sendo o programa lançado oficialmente em Florianópolis no mês de Novembro de 2013 pelo Serviço Nacional de Aprendizagem do Cooperativismo de Santa Catarina - SESCOOP, durante o 11º Encontro Estadual de Mulheres. O programa Mulheres cooperativistas tem por objetivo melhorar a participação das mulheres no quadro social das cooperativas através de educação cooperativista e aprimoramento dos seus conhecimentos (REVISTA DAS COOPERATIVAS, 2013).

O programa é composto pelas cooperadas, esposas, filhas de cooperados e colaboradores de cooperativas catarinenses atuantes nas mais diversas atividades econômicas. Este programa foi dividido em quatro etapas: preparação, lançamento, formação modular e implantação de núcleos femininos, a fim de promover a disseminação das premissas cooperativistas e desenvolvimento de atitudes, habilidades e competências necessárias para melhor atuação das mulheres no quadro social das cooperativas, conforme Quadro 02:

\section{Quadro 02 - Etapas programa mulheres cooperativistas}

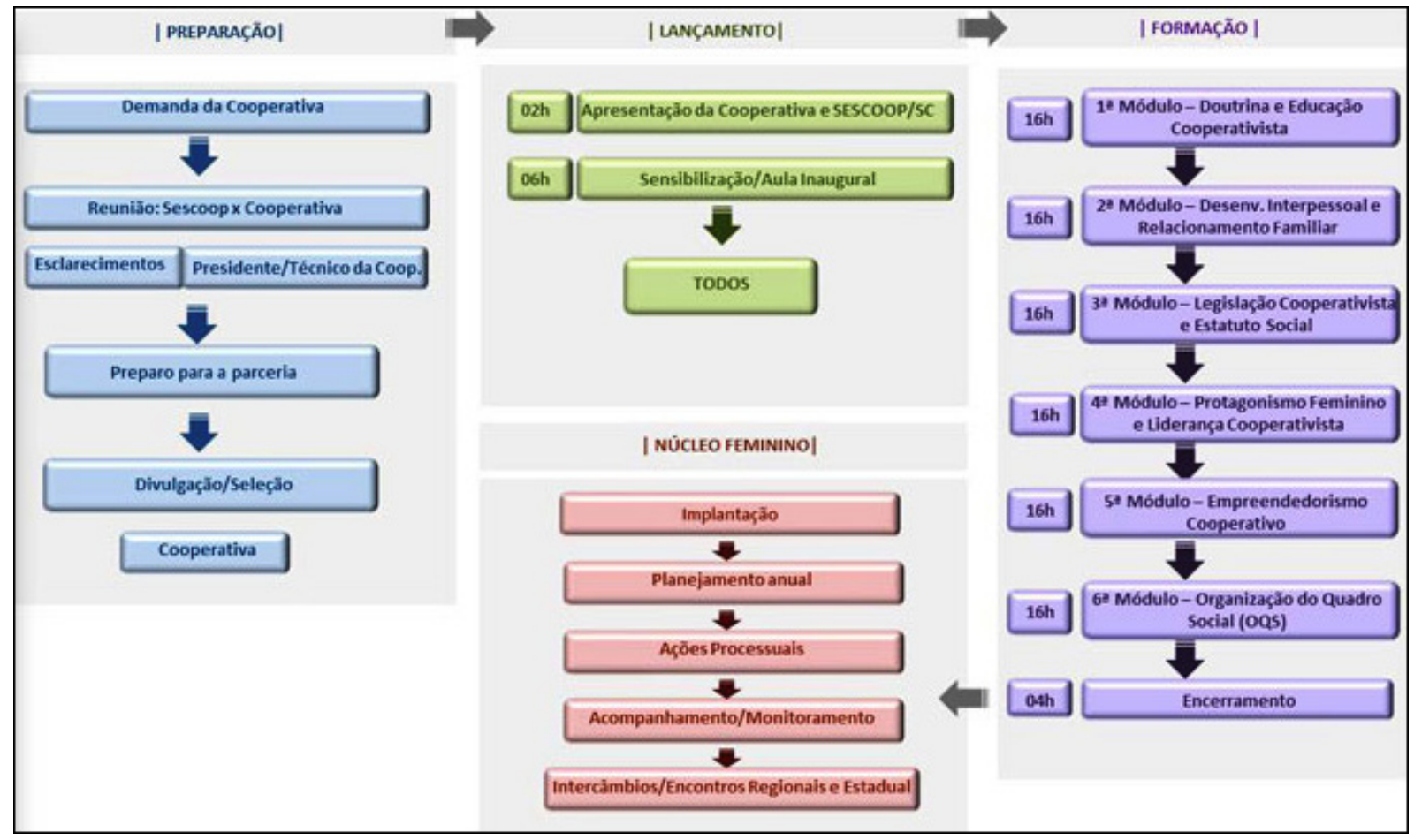

Fonte: SESCOOP - SC (2017)

\section{O programa mulheres cooperativistas é dividido em seis módulos sendo estes:}

MÓDULO I - Doutrina e Educação Cooperativista: Tem por finalidade aproximar a mulher de sua cooperativa por meio da compreensão da doutrina cooperativista a fim de que utilizem sua influencia e conhecimento para que a família associada desempenhe seu papel de cooperados.

MÓDULO II - Desenvolvimento Interpessoal e Relacionamento Familiar: Despertar na participante seu autoconhecimento, aprofundando e descobrindo o modo de lidar com as 
pessoas e familiares, demonstrando sua influência no meio familiar além de debater sobre maiores dificuldades familiares e soluções para as mesmas.

MÓDULO III - Sociedades Cooperativas: Objetiva o conhecimento e compreensão do conceito, estrutura, características, funcionamento e desafios de uma cooperativa, visando maior participação das famílias cooperadas.

MÓDULO IV - Protagonismo Feminino e Liderança Cooperativista: Propõe a reflexão das participantes sobre o papel da mulher na família, na comunidade e na cooperativa com propósito de que as mesmas percebam a importância de seu protagonismo na cooperativa e papel de líder na organização.

MÓDULO V - Empreendedorismo Cooperativo: Conscientiza as participantes de sua força e capacidade de influência nos resultados da cooperativa, com intuito de que ampliar seu entendimento quanto a sua colaboração no fortalecimento do núcleo familiar, da cooperativa e do cooperativismo.

MÓDULO VI - Organização do Quadro Social (OQS): Desenvolvimento do entendimento das participantes quanto a valorização da organização do quadro social e seu papel nos processos decisórios e de autogestão da cooperativa (SESCOOP, 2017).

O programa tem como metodologia a organização de grupos, com propósito de melhor interação de alunas e professor, tanto no desenvolvimento teórico quanto nas atividades realizadas a fim de promover a vivência do cooperativismo. Cada módulo possui 16 horas de duração e ao final dos mesmos faz-se a criação e organização dos núcleos femininos, se as mulheres em questão aceitarem fazer parte do mesmo (SESCOOP, 2017).

Ao final do último módulo, as participantes recebem todas as informações necessárias sobre a finalidade e tarefas atribuídas ao núcleo feminino e em coletividade as mesmas decidem se aceitam integrar o núcleo feminino da cooperativa.

Em cerimônia organizada pela cooperativa é realizada a formatura das mulheres cooperativistas, que recebem o certificado de conclusão de curso. Isso ocorre para as participantes que obtiveram no mínimo $80 \%$ de frequência nos encontros, estando assim aptas a participarem ativamente do quadro social da cooperativa (SESCOOP, 2017).

Depois de formadas, as mulheres cooperativistas participam de encontros anuais, o qual conta com a presença de todas as cooperativas, e com sua formação surgem compromissos que proporcionaram participação nas assembleias, no quadro diretivo, núcleos e comitês da cooperativa em que esta inserida. A cooperativa junto ao SESCOOP continuará a dar apoio para as mulheres, disponibilizando sempre cursos e treinamentos a fim de promover a continuidade do aprimoramento e desenvolvimento de seus conhecimentos (SESCOOP, 2017).

Segundo Hoffman (2013), a mulher cooperativista tem o dever de se envolver com as atividades da cooperativa, buscando sempre a compreensão de assuntos relacionados aos negócios e empreendimentos, respeitando e compreendendo as diversas ideias e expondo suas opiniões livremente, resultando assim em uma mulher participativa e motivada. Com o cooperativismo foi possível inspirar a mulher a possuir maior desempenho crítico, incentivando-as a expor suas ideias sem que se sintam coagidas e incentivar o interesse de outras mulheres a fazerem parte do núcleo feminino. 


\section{MATERIAIS E MÉTODOS}

A presente pesquisa caracteriza-se como exploratória, descritiva e utilizou-se pesquisa bibliográfica e de pesquisa de campo.

Para isso o objeto de estudo foi uma cooperativa de Santa Catarina, a qual vem inserindo em seu quadro organizacional esposas, filhas de cooperados e cooperadas. Tendo em vista a iniciativa da cooperativa nesta inserção, procurou-se compreender a inserção na vida das mulheres e no cotidiano da cooperativa. Sendo assim, foi entregue 40 instrumentos de pesquisa com 11 perguntas. $\mathrm{O}$ retorno foi de 18 instrumentos, aos quais foi realizados a análise de dados. $\mathrm{O}$ instrumento apresentava-se com perguntas fechadas, porém com espaços para que a respondente pudesse escrever relatos de mudanças pós-inserção no núcleo feminino.

Em uma segunda etapa foi feito entrevista em profundidade com o diretor responsável pela cooperativa em questão. Tal entrevista teve como finalidade entender como a gestão da cooperativa entende a iniciativa e quais os possíveis impactos que o respondente entende com tal programa.

Para análise dos dados utilizou-se o método qualitativo em análise de dados coletados através de amostra não probabilística por acessibilidade. $O$ método qualitativo refere-se à observação dos fatos sob o olhar analítico do pesquisador inserido na organização em questão (TEIXEIRA, 2005).

\section{RESULTADOS E DISCUSSÕES}

No capítulo que se segue será abordada a análise de pesquisa realizada com as mulheres integrantes do núcleo feminino de uma cooperativa catarinense, sendo que de quarenta questionários aplicados, obteve-se retorno de dezoito questionários respondidos. Nessa seção aborda os itens como o perfil das entrevistadas, nível de satisfação pelo núcleo e da sua participação, satisfação em ter a possiblidade de opinar e em seguida apresenta os relatos das entrevistadas. $\mathrm{Na}$ segunda seção apresenta-se a visão do gestor da cooperativa referente à inserção do núcleo e quais as mudanças por ele percebidas.

\section{Perfil de mulheres entrevistadas}

O Quadro 03 (três) apresenta os dados sócio-técnicos das respondentes. Pode-se observar que a participação maior no núcleo ocorre das mulheres de São João do Sul e Torres. Identificase também que 50\% (9 entrevistadas) possuem idade entre 45 a 54 anos. Sendo assim pode-se dizer que na sua maioria as entrevistas são jovens adultas.

No instrumento proposto as mulheres foram questionadas se as mesmas eram solteiras, entendendo-se que são associadas, se eram casadas, ou seja, esposa de associados, separadas/ divorciadas ou viúvas. Sendo assim, contatou-se que 83\% (15 entrevistadas) das mulheres são casadas. 


\begin{tabular}{|c|c|c|c|}
\hline \multicolumn{2}{|l|}{ Alternativa } & Frequência & Percentual (\%) \\
\hline \multirow{6}{*}{ Cidade onde residem } & São João do Sul & 7 & 38,89 \\
\hline & Torres & 6 & 33,33 \\
\hline & Turvo & 2 & 11,11 \\
\hline & Araranguá & 1 & 5,56 \\
\hline & Forquilhinha & 1 & 5,56 \\
\hline & Meleiro & 1 & 5,56 \\
\hline \multirow{5}{*}{ Faixa etária } & De 20 a 24 anos & 0 & 0,00 \\
\hline & De 25 a 34 anos & 0 & 0,00 \\
\hline & De 35 a 44 anos & 2 & 11,11 \\
\hline & De 45 a 54 anos & 9 & 50,00 \\
\hline & De 55 anos ou mais & 7 & 38,89 \\
\hline \multirow{4}{*}{ Estado civil } & Solteiro & 1 & 5,56 \\
\hline & Casado & 15 & 83,33 \\
\hline & Separado/ Divorciado & 0 & 0,00 \\
\hline & Viúva & 2 & 11,11 \\
\hline \multirow{4}{*}{ Situação cooperativista } & Associada & 5 & 27,78 \\
\hline & Filha de associado & 0 & 0,00 \\
\hline & Esposa de associado & 13 & 72,22 \\
\hline & Outros & 0 & 0,00 \\
\hline \multirow{3}{*}{ Situação profissional } & Sim & 3 & 16,67 \\
\hline & Não & 15 & 83,33 \\
\hline & $\begin{array}{l}\text { Não, mas estou } \\
\text { procurando. }\end{array}$ & 0 & 0,00 \\
\hline \multirow{3}{*}{ Ano de ingresso no núcleo feminino } & Ano 2011 & 5 & 27,78 \\
\hline & Ano 2012 & 11 & 61,11 \\
\hline & Não informou & 2 & 11,11 \\
\hline
\end{tabular}

Fonte: Dados obtidos pela pesquisa (2014)

Através dos dados obtidos, observou-se que das 18 entrevistadas, 13 são esposa de associado, ou seja, mais de $50 \%$ das entrevistadas e o restante trata-se de associadas. Não obteve casos de filhas de associados que fazem parte do núcleo, sendo que as mesmas já fazem parte do quadro de associados da cooperativa em estudo, consequentemente identificando-se na pesquisa como associada.

Analisando ainda o Quadro 03, pode-se constatar que das 18 mulheres do núcleo entrevistadas, 83,33\% (15 entrevistadas) das mulheres não apresentam um emprego formal, ou seja, cuidam do lar, dos filhos, da horta, tiram leite e ajudam esposo na agricultura em geral.

No decorrer do questionário foi perguntado as mulheres o ano em que ingressaram no núcleo feminino. Conforme constatado, observou-se que na maioria 61,11\% (11 entrevistadas) dizem ter ingressado no núcleo em 2012, pois foi o ano que o projeto começou, 27,78\% (5 entrevistadas) dizem ter ingressado em 2011, ano em que a ideia surgiu, porém neste ano o núcleo ainda não estava sendo praticado pela cooperativa em questão, portanto acredita-se que as mesmas tenham se confundido, e por fim 11,11\% (2 entrevistadas) não souberam informar o ano em que ingressaram no núcleo. 


\section{VISÃO DE MULHERES EM RELAÇÃO AO PROJETO “NÚCLEO FEMININO"}

\section{a) Nível de satisfação}

Todas as entrevistadas encontraram-se satisfeitas com o programa implantado pela cooperativa, sendo que mais da metade $(83,33 \%$ entrevistadas) relatam estar muito satisfeita e $16,67 \%$ satisfeitas. Não houve incidência de insatisfação por parte das respondentes, mostrando que apresentam satisfação com o núcleo feminino.

\section{b) Satisfação de participação}

As mulheres demonstraram estar satisfeitas com sua participação na cooperativa por intermédio do núcleo feminino, porém 11,11\% (2 entrevistadas) se posicionaram neutras, sendo assim, estas entendeu-se que possuem participação pouco expressiva na cooperativa.

\section{c) Recomendação do núcleo}

Neste questionamento permitiu conhecer se as mulheres entrevistadas recomendariam a inserção no núcleo feminino para outras mulheres. Observou-se que a recomendação do núcleo para outras mulheres foi unânime, ou seja, todas as entrevistadas estão muito satisfeitas com o projeto e consequentemente recomendariam a inserção no núcleo para outras mulheres que ainda não fazem parte do mesmo. Todas as entrevistadas recomendam o núcleo, isso mostra que o objetivo principal do núcleo feminino esta sendo atingido pelos gestores organizadores deste grupo.

\section{d) Tomada de decisão na cooperativa}

Procurou-se identificar como as mulheres se sentem perante a possibilidade de opinar nas decisões da cooperativa, e consequentemente se as mesmas realmente estão podendo opinar. Das respondentes apenas 3 entre 18 entrevistadas apresentaram-se neutras, porém as demais manifestaram-se muito satisfeitas com a possibilidade que o programa "Núcleo feminino" thes proporcionou.

\section{e) Relato de mudanças pós-inserção no núcleo feminino.}

Em resposta ao questionamento sobre as mudanças ocorridas em suas vidas após participação no núcleo feminino, alguns relatos foram feitos pelas respondentes nesta questão de pergunta aberta.

Foi muito importante porque adquiri conhecimento de como funciona uma cooperativa e aprendemos a dar valor ao ser humano, respeitando as diferenças (R16). Me ajudou a me autoconhecer e despertou certas aptidões que eu desconhecia ter. Também me possibilitou aumentar meu círculo de amizade (R8) [Grifo nosso].

Em resposta ao questionamento, a respondente R16 e R8 relata que por meio de conhecimentos disponibilizados pelo núcleo feminino, foi possível adquirir novos laços de amizades e obter melhor visão de como uma cooperativa é constituída e seu funcionamento, aprendendo assim a valorizá-la. 
"Não só em relação à cooperativa, mas também houve mudanças em relacionamento com família, com a comunidade, e muitas outras informações sobre a mulher" (R7). Me sinto mais auto confiante, aumentou meu círculo de amizades, aprendi mais sobre os assuntos da cooperativa e seu funcionamento. Aprendi ter mais tempo para mim (R15) [Grifo nosso].

Conforme relato respondente $\mathrm{R} 7$, além de adquirirem maior integração com a família e adquirirem novas amizades e conhecimentos. Com o núcleo elas relatam ter reconquistado sua autoconfiança e autoestima, pois sentem-se mais confiantes.

[...] Conhecemos melhor a cooperativa, o desenvolvimento, o trabalho, a integração dos associados e devemos nos ajudar para obtermos cooperativas fortes para um futuro melhor para nossas famílias (R3). Posso dizer que através do núcleo feminino, ampliei a minha visão sobre várias coisas, como ver a propriedade como uma empresa e administrá-la com maior seriedade. Já na parte pessoamulher, elevou minha autoestima e segurança para encarar os desafios que a vida e a sociedade nos trazem. (R10) [Grifo nosso].

Na percepção das respondentes com o núcleo feminino a mulher cooperativista desenvolveu sua autoconfiança e consequentemente demonstra que adquiriu noção de sua capacidade de influência no zelo de sua propriedade, ampliando sua visão no mundo dos negócios e adquirindo maior discernimento sobre sua responsabilidade na sociedade.

[...] eu defendo com muito amor, porque conheço o que defendo A COOPERATIVA é meu coração (R6) [Grifo nosso].

Perante declaração em destaque da respondente R6, é possível perceber o grande contentamento e satisfação com o programa núcleo feminino, isso foi observado por todas se comprometem com a cooperativa com amor e dedicação.

\section{VISÃO DE GESTOR EM RELAÇÃO AO PROJETO NÚCLEO FEMININO}

\section{a) Depoimento do Presidente da cooperativa selecionada}

O presidente da cooperativa em estudo relata a importância das mulheres na cooperativa por meio do núcleo e qual os impactos desta inserção para a cooperativa.

"Desde quando surgiu a ideia de criar o núcleo feminino, houve algumas dúvidas do que seria o núcleo feminino. Então, para suprir essa dúvidas vieram instrutores da OCESC para explicar para nós que o núcleo feminino seria o convite a algumas esposas de associados e um trabalho que iria trazer o conhecimento de cooperativismo para essas esposas porque ainda tínhamos certa resistência do associado ou falta de interesse do associado de transmitir para família em casa aquilo que acontece na cooperativa, porque o associado é sócio da cooperativa, mas a esposa também faz parte da família e também é uma pessoa tão interessada quanto o associado para saber o que acontece na cooperativa e às vezes a esposa pergunta e o associado possui dificuldade em repassar para a esposa ou ate por desinteresse o que acontece na cooperativa" [Grifo nosso].

O programa "núcleo feminino" foi implantado em 2013 através da OCESC que junto às cooperativas proporcionou as mulheres melhor esclarecimento quanto ao intuito do projeto e seus benefícios. Sendo assim o programa passou por quatro etapas; preparação, lançamento, 
formação modular e implantação do núcleo feminino tendo por objetivo melhorar a participação das mulheres no quadro social da cooperativa.

[...] a partir do momento que iniciamos, elas criaram bastante interesse porque realmente foi trazido para elas como funciona uma cooperativa, a estrutura desde o início entrada de sócio, participação que é muito importante, a fidelidade, como se produz, onde se compra o insumo para levar para a propriedade, preço de custo, qualidade de cada produto, enfim toda aquela situação que a cooperativa já oferece para o associado, só porem não tava sendo bem aproveitado porque não se tinha informação, então essa informação veio através de pessoas bem preparadas [Grifo nosso].

Durante o programa as mulheres obtiveram acesso aos conhecimentos dos princípios e educação cooperativista, desenvolvimento interpessoal e relacionamento familiar, sociedade cooperativa, protagonismo feminino e liderança cooperativista, empreendedorismo cooperativo e organização do quadro social da empresa. Perante isso pode-se afirmar que com o núcleo feminino as mulheres adquiriram melhor compreensão do que é uma cooperativa, como ela funciona e como contribuir para seu crescimento.

"O diferencial daí para frente foi o interesse de mais alguns associados, que viram que elas chegaram com uma imagem diferente em casa da cooperativa e começaram a questionar os esposos associados por que disso e por que daquilo, então a empresa percebeu que houve maior participação das esposas e associados nas comunidades. Após a ideia do núcleo a empresa esta vem percebendo maior desempenho e informação chegando a residência dos associados, e assim hoje não somos mais tão questionados em relação a cooperativa porque as pessoas estão bem informadas sobre o que acontecesse na cooperativa e o que significa cooperativismo. A importância geral da criação do núcleo é trazer a família do associado para dentro da cooperativa" [Grifo nosso].

Observa-se que a prática realmente está em consonância com o cunho teórico, pois observouse nos relatos que a mulher vem deixando de lado de ser apenas mantenedora lar e aos poucos vem conquistando outros espaços, hoje ela ocupa vários cargos de responsabilidade, colaborando no aumento da renda familiar e contribuindo com a força produtiva do país (VIEIRA; SILVA, 2001).

"O núcleo começou com um grupo de senhoras associadas e esposas de associados, onde elas aprenderam o quanto é interessante a cooperativa ir na comunidade e na propriedade delas, então o objetivo é trazer esse conhecimento para a família e assim integrar elas a comunidade cooperativa, e consequentemente a cooperativa e o associado ganham, afinal a cooperativa ganhando o associado também ganha com isso" [Grifo nosso].

Durante entrevista o Presidente afirma que em uma cooperativa não há individualismo sendo assim é necessário que os associados estejam conscientes da importância do trabalho em equipe, afinal, se uma ganha, todos ganham.

"Através do núcleo elas adquiriram conhecimento sobre a cooperativa e participação, pois a participação delas na cooperativa pode ser vista através das assembleias que agora tem uma participação maior de associados, porque elas participando de assembleias, de reuniões e podendo expressar sua opinião sobre a cooperativa, e isso deixa a diretoria e o presidente mais respaldado, porque existe questionamento por parte delas, e para o dia a dia de trabalho da cooperativa e assim ela vem trazendo mais segurança para presidente e para diretoria, porque as coisas são debatidas não só em assembleias, mas também no dia a dia da cooperativa" [Grifo nosso]. 
Perante depoimento do entrevistado percebe-se a satisfação do mesmo com a participação feminina, pois através no núcleo feminino a mulher adquiriu grande influência e voz ativa em seu lar, pois agora ela possui conhecimento suficiente para participar de reuniões e assembleias a fim de contribuir com ideias e opiniões, as quais deixam a presidência e diretoria mais confiantes em suas tomadas de decisões.

"Deu-se o privilégio de no sul do estado de SC termos duas cooperativas selecionadas para executarem o projeto piloto, e em 2012 começou esse trabalho onde nossa cooperativa foi escolhida em todo estado de SC para fazer esse projeto que deu certo. Essa participação continua e estamos agora com a ideia de formar outro núcleo feminino, trazer mais pessoas para dentro, e com certeza quem vai ganhar é elas e a cooperativa" [...] a participação do associado aumentou principalmente nos locais onde foi implantado o núcleo, fazendo com que o associado venha comprando mais, aumentando a quantia de depósitos de arroz e fazendo as informações chegarem para pessoas que não participam do núcleo [...] E assim surge interesse de outras pessoas no núcleo e na cooperativa, pois se o projeto continua é porque é bom e deu certo" [Grifo nosso].

Além de privilegiado por sua cooperativa ter sido selecionada para implantação do projeto, o entrevistado encontra-se realizado com a repercussão positiva que o mesmo vem obtendo, repercussão essa que ele atribui as integrantes do núcleo e associados que devido ao contentamento com o programa, indicam a participação para outras mulheres.

[...] associados não conheciam outras filiais e agricultores como eles. E hoje com o núcleo eles possuem oportunidade de conhecer outras cooperativas de outros estados bem maiores que a nossa, que possuem este mesmo trabalho desenvolvido a mais tempo que nós, então através de visitas nestas cooperativas elas viram o quanto foi interessante formar esse núcleo feminino, formar esse grupo de pessoas para interagir e conhecer o que é o cooperativismo[...], e isso é muito gratificante para nós. Quando elas participam surgem várias opiniões e informações que chegam e essa participação delas dá mais segurança para o esposo associado que se torna mais participativo. O diferencial do núcleo feminino é realmente o apoio que elas proporcionam [...] [Grifo nosso].

Torna-se gratificante segundo relato do entrevistado observar o interesse e a participação da família cooperada, tendo em vista que em retrospecto anterior o núcleo, os associados possuíam baixo interesse e participação nas assembleias, cenário este, que vem mudando através da participação feminina na cooperativa, proporcionando maior apoio aos esposos associados em suas decisões.

[...] atualmente elas estão com ideias de inovar algumas coisas na cooperativa e nós estamos aprimorando na medida do possível para ver, e possuímos para o futuro alguma coisa já bem adiantada em relação a estas novas ideias, que no momento a empresa se reserva em divulgar isso, porque é um projeto que ainda esta em desenvolvimento e acreditamos que vai fazer diferença no futuro com certeza, isso vai ser divulgado somente ano que vem. Esta sendo encaminhada também uma possível participação delas como diretoras ou conselheiras fiscais, afinal elas têm direito também. Como nós possuímos uma cooperativa diversificada [...] elas sempre possuíram participação em um determinado ramo que não é só dos homens, pois a mulher tem um pouco mais de afinidade ate para poder tirar algumas conclusões [Grifo nosso].

Quanto às opiniões e ideias prestadas pelas mulheres dentro da cooperativa, o entrevistado relata que o resultante dessas ideias propostas pelo núcleo feminino, um grande projeto esta em fase incubadora, projeto este, que a empresa no momento prefere deixar em sigilo, pois o mesmo 
ainda encontra-se em fase de aprimoramento. Há previsão que em breve as mulheres poderão fazer parte do quadro social da cooperativa em cargos relevantes.

A partir de depoimento prestado pelo presidente da cooperativa, percebeu-se que o mesmo encontra-se muito satisfeito com os resultados obtidos a partir da inserção do núcleo feminino, pois identificou que a partir da implantação do projeto houve uma maior participação dos associados nas decisões da cooperativa além de melhorar a relação entre a família do associado e a cooperativa.

Por fim, perante os resultados obtidos por meio de questionários aplicados com mulheres participantes do núcleo feminino e entrevista realizada com gestor da cooperativa em estudo, constatou-se que não há insatisfação por parte das mulheres respondentes, sendo que todas recomendariam a inserção no núcleo para outras muheres e o gestor declara estar satisfeito com os resultados obtidos, sendo assim, a gestão do núcleo demonstra ser bem sucedida. Deve ser levado em conta que houve uma participação pequena na devolutiva do instrumento e que as não respondentes pode haver descontentamento que não foi evidenciado na presente pesquisa. Porém a convergências das respostas é um indicativo que o projeto é positivo e que a meta a qual é destinado pode ser considerada como atingida.

\section{CONSIDERAÇÕES FINAIS}

Seja no lar ou em instituições, ocupar um cargo de líder hoje é uma árdua tarefa para ambos os gêneros. Para ser um líder é necessário ter empatia e saber guiar e conquistar as pessoas ao seu redor, a fim de que as mesmas o sigam naturalmente objetivando um bom trabalho em equipe. Muitas mulheres apresentam isso como um dom natural de influenciar e liderar pessoas, e este dom torna-se hoje um diferencial em sua inserção no mercado de trabalho.

O presente estudo foi realizado com o intuito de conhecer e identificar o modo de inserção do núcleo feminino em uma cooperativa. Perante depoimento adquirido por questionários, conclui-se que as mulheres respondentes encontram-se satisfeitas com os propósitos e resultados do programa "núcleo feminino", pois relatam que adquiriram maior conhecimento sobre cooperativa, obtiveram maior integração com a família, novas amizades, reconquistaram sua autoconfiança, autoestima, e sentem-se mais confiantes e participativas.

Em contrapartida foi possível identificar por meio de entrevista realizada com gestor que a cooperativa em questão também se beneficiou, pois identificou que a partir da implantação do projeto houve uma maior participação dos associados nas decisões da cooperativa além de melhorar a relação entre a família do associado e a cooperativa.

Devido ao sucesso presenciado pelo programa, sugere-se que o mesmo fosse aberto para além das associadas, esposas de associados e filhas, mas para funcionários e clientes, a fim de conquistar maior fidelização e compreensão dos mesmos quanto a sua importância para a cooperativa.

Por fim, pelo fato de a pesquisa ter se limitado apenas a uma cooperativa do Sul de Santa Catarina, para que haja prosseguimento de estudos do tema sugere-se para vindouras pesquisas estudos aprofundados sobre o gênero feminino dentro de outras cooperativas, bem como uma possível reaplicação do instrumento na mesma cooperativa visando uma maior sensibilização a fim de abarcar um maior número de respondente para uma comparação com os resultados apresentados no presente trabalho. 


\section{Agradecimentos}

Ao Curso de Administração/UNESC e ao Programa de Pós Graduação em Desenvolvimento Socioeconômico (PPGDS/UNESC).

\section{REFERÊNCIAS}

ANDREOLI,T.P.; BORGES,W.A. Empreendedorismo feminino: uma análise do perfil empreendedor e das dificuldades enfrentadas por mulheres detentoras de um pequeno negócio. Disponível em: >http://www.administradores.com.br/producao-academica/ empreendedorismo-feminino-uma-analise-do-perfil-empreendedor-e-das-dificuldadesenfrentadas-por-mulheres-detentoras-de-um-pequeno-negocio/410/< Acesso em: 22 Nov 2014.

BRUSCHINI, C.; PUPPIN, A. B. Trabalho de mulheres executivas no Brasil no final do século XX. Disponível em: <http://www.scielo.br/pdf/cp/v34n121/a06n121.pdf >. Acesso em 19 Março 2014

CARREIRA, D.; AJAMIL,M.; MOREIRA, T.Mudando o mundo: a liderança feminina no século 21. São Paulo: Cortez, 2001. 232 p

CERVO, A. L.; BERVIAN, Pedro Alcino. Metodologia científica. 4 ed. São Paulo: Makron Books, c1996. xiv 209 p. 2002. 242 p.

A. L.; BERVIAN, P. A. Metodologia científica. 5. ed São Paulo: Prentice Hall,

CRIPE, E. J.; MANSFIELD, R. Profissionais disputados: as 31 competências de quem agrega valor nas empresas. Rio de Janeiro: Campus, 2003, p. 14; 25-7.

GOMES, A. F. O outro no trabalho: Mulher e gestão. Disponível em: < http://www.ead. fea.usp.br/cad-pesq/arquivos/313.pdf>. Acesso em: 19 Março 2014

HERNÁNDEZ SAMPIERI, R.; FERNÁNDEZ COLLADO, C.; BAPTISTA LUCIO, P. Metodologia de pesquisa. 3. ed São Paulo: McGraw-Hill, 2006. 583p.

HOFFMAN, E. F. A mulher e o Cooperativismo. Florianópolis: Impresul Indústria Gráfica Ltda, 2013. 42 p.

MONJE-REYES, P. Economía solidaria, cooperativismo y descentralización: la gestión social puesta en práctica. Cad. EBAPE.BR, Rio de Janeiro, v. 9,n. 3,Sept. 2011. Disponível em: <http://www.scielo.br/scielo.php?script=sci_arttext\&pid=S167939512011000300003\&lng=en\&nrm=iso >. Acesso em: 13 Maio 2014. >http://dx.doi. org/10.1590/S1679-39512011000300003<. 
OCB/SESCOOP - Sindicato e Organização das Cooperativas Brasileiras no Estado e Serviço Nacional de Aprendizagem do Cooperativismo. Disponível em: <http://www. ocbgo.org.br/cooperativismo/o-que-e-o-cooperativismo/simbolos-do-cooperativismo/>. Acesso em: 23 Maio 2014

OCESC - Organização das Cooperativas do Estado de Santa Catarina. 2013. Disponível em: >http://www.ocesc.org.br/noticias_eventos/noticias_eventos.php?id=8427< Acesso em: 19 Março 2014.

. Organização das Cooperativas do Estado de Santa Catarina Disponível em: $>$ hhttp://www.ocesc.org.br/mulheres/index.php<. Acesso em: 21 Maio 2014

OLIVEIRA, F. Os sentidos do cooperativismo de trabalho: as cooperativas de mão-deobra à luz da vivência dos trabalhadores. Psicol. Soc., Porto Alegre, v. 19,n. spe, 2007. Disponível em:<http://www.scielo.br/scielo.php?script=sci_arttext\&pid=S010271822007 000400011\&lng=en\&nrm=iso >. Acesso em: 13 Maio 2014. >http://dx.doi.org/10.1590/ S0102-71822007000400011<

OLIVEIRA, J. F.; MARINHO, R. M. Liderança: uma questão de competência. São Paulo: Saraiva, 2005.358 p.

OLIVEIRA, S. L. Tratado de metodologia científica: projetos de pesquisas, TGI,TCC, monografias, dissertações e teses. São Paulo: Pioneira, 1999.320 p.

PE, D. Oito tipos de líderes que todo líder deveria conhecer: a nova psicologia em liderança de sabedoria e de profiling que ninguém lhe ensina em Harvard. Rio de Janeiro: Qualitymark, 2008.290 p.

PEREIRA, R. S.; SANTOS, D. A.; BORGES, W. A Mulher no Mercado de Trabalho. Disponível em:<http://www.joinpp.ufma.br/jornadas/joinppl1/pagina_PGPP/Trabalhos/ EixoTematicoD/321waleska_Rosangela_Danielle.pdf>. Acesso em: 19 Maio 2014

PINHO, D. B. O cooperativismo no Brasil: da vertente pioneira à vertente solidária. São Paulo: Saraiva, 2004. 357 p.

PREFEITURA MUNICIPAL DE TURVO - SC. Jan 2014. Disponível em: > http:// www.turvo.sc.gov.br/cms/pagina/ver/codMapaItem/22089\#.U3LHTnY9bFw $<$ Acesso em: 13 Maio 2014

RECH, D. Cooperativas: uma alternativa de organização popular. Rio de Janeiro: DP\&A, 2000. 190 p.

REVISTA DAS COOPERATIVAS. Mulheres cooperativistas já somam 411 mil em santa Catarina, ano XI, edição 29, Out/Nov/Dez, 2013. 
RICCIARDI, L.; LEMOS, R.J. Cooperativa, a empresa do século XXI: como os países em desenvolvimento podem chegar a desenvolvidos. São Paulo: LTR, 2000, 183 p.

SESCOOP - Serviço Nacional de Aprendizagem do Cooperativismo. Programa Mulheres Cooperativistas. Disponível em: http://www.sescoopsc.org.br/secao/mulheres Acesso em: 03 Mar 2017.

SCHLICKMANN, E.; PIZZARRO, D. A evolução da mulher no mercado de trabalho: uma abordagem sob a ótica da liderança. Disponível em: >http://revistaborges.com.br/ index.php/borges/article/viewFile/43/117< Publicado em: 2013. Acesso em: 22 Maio 2014.

SOUZA, E. S.; SANTOS, S. P. Mulheres no mercado de trabalho: Um estudo com estudantes universitários Do curso de administração de uma Faculdade particular de São Paulo (SP). Revista dos discentes da Faculdade Eça de Queiros, n. 3, maio 2014. Disponível em: >http://www.faceq.edu.br/e-faceq/downloads/numero03/3-mulheres-nomercado-de-trabalho-um-estudo-de-caso.pdf< Acesso em: 20 Nov 2014.

TEIXEIRA, E. As três metodologias: acadêmica, da ciência e da pesquisa. Petrópolis, RJ: Vozes, 2005. $203 \mathrm{p}$

TORREÃO, N; A liderança feminina no desenvolvimento sustentável. Revista Àrtemis. V.7 p. 101-121. 2007. Disponível em:>http://periodicos.ufpb.br/ojs/index.php/artemis/ article/view/2155/1913< Acesso em: 17 Nov 2014

VIEIRA, G. F. N.; SILVA, T. D. L. Como elas veem o mundo dos negócios? Lutas, Conquistas e Estereótipos da mulher no mercado de trabalho a partir da percepção de alunas concluintes do curso de Administração. In: 10 Convibra - Administração - 2013. Anais... Disponível em:

<http://www.convibra.com.br/upload/paper/2013/34/2013_34_7275.pdf> Acesso em: 22 Maio 2014.

VEIGA, S.M. Cooperativismo: uma revolução pacífica em ação. Rio de Janeiro: DP\&A, $2002.106 \mathrm{p}$. 